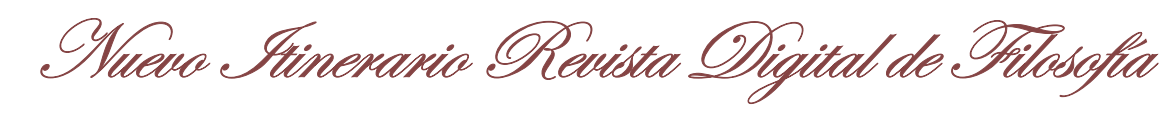

ISSN 1850-3578

\title{
Memoria y Conocimiento Histórico. El debate filosófico contemporáneo atravesado por la impronta platónica
}

Guillermo A. Vega*

Plantear hoy en día un trabajo sobre memoria del pasado reciente es ingresar en un terreno que en los últimos veinte años ha sido -y sigue siendo- fuertemente transitado tanto en nuestro país como en el mundo por las ciencias sociales. Disciplinas como la sociología, la antropología y la historia retomaron las herramientas de análisis de los desarrollos que, desde la década del '60, en Europa se venían produciendo alrededor del mismo campo temático a partir del problema planteado por la conservación de la memoria del genocidio judío durante el nazismo. Paralelamente al desarrollo de estas investigaciones, la filosofía ha tenido una presencia en buena medida "dosificada" alrededor de los tópicos en discusión. Exceptuando trabajos específicos sobre la materia realizados por pensadores de renombre en el campo filosófico contemporáneo -me refiero en particular a Paul Ricoeur ${ }^{1}$ y Giorgio Agamben ${ }^{2}$-, el resto de las tradiciones filosóficas no se ha visto mayormente obligado a incorporarse a los debates en torno de la memoria y del pasado reciente. Esto, claro está, si exceptuamos la presencia oblicua que algunos problemas y posiciones (i.e.: la filosofía del lenguaje, las reflexiones en torno de la experiencia, los problemas alrededor de la epistemología historia y de la filosofía de la historia) han tenido en el tratamiento de la memoria del pasado reciente desde las ciencias sociales.

Más allá de este diagnóstico imperfecto cabe constatar que, a pesar de su presencia más bien difusa en el debate filosófico contemporáneo, la reflexión sobre la memoria ha estado presente desde los comienzos de la historia de la filosofía en la Grecia clásica. Es Platón quien, entre los siglos V y IV a.C., da inicio a la tematización de la memoria emplazándola dentro del problema mayor del conocimiento. Partiendo del supuesto de la preexistencia de las almas, el filósofo griego sostenía que el acceso a las Ideas era posible a través de un proceso de reminiscencia (anamnesis) a partir del cual el conocimiento se configuraba como el recuerdo de aquello presenciado por el alma en un momento anterior a la coexistencia con

\footnotetext{
* Profesor y Licenciado en Filosofía. Docente a cargo de la cátedra "Filosofía del Derecho". Facultad de Humanidades. Universidad Nacional del Nordeste. E-mail: gui_vega@argentina.com

${ }_{1}^{1}$ Ricoeur, Paul. La memoria, la historia, el olvido, Bs. As., Fondo de Cultura Económica, 2008.

${ }^{2}$ Agamben, Giorgio. Lo que queda de Auschwitz. El archivo y el testigo. Homo Sacer III, Valencia, Pre-Textos, 2000.
} 
el cuerpo. ${ }^{3}$ La inversión término a término de la fórmula platónica "conocer es recordar" articuló los elementos y, por ende, el terreno sobre el cual se configuraron buena parte de los problemas en relación con el pasado construidos a lo largo de la historia del pensamiento en Occidente. Baste señalar al respecto que la aparición de la historiografía tuvo lugar en la mudanza de los términos del postulado platónico, es decir, "recordar" se volvió “conocer". En consecuencia -y esta es una de las ideas que quisiera tratar de sostener a lo largo del presente trabajo-, el espacio problemático inaugurado por el platonismo, alrededor de la relación entre conocimiento y recuerdo/reminiscencia, sigue diagramando buena parte del debate contemporáneo sobre el vínculo conflictivo entre memoria y conocimiento histórico. Asimismo, intentaré sostener que la posición de M. Foucault con respecto a la historia reformula, en buena medida, la fórmula platónica y permite, por ende, atender los sucesos pretéritos en relación con el espacio político a partir de los modos de autoconstitución de sí, dejando de lado los problemas relativos a la verdad del conocimiento histórico y al deber de recordar.

\section{La historia, el conocimiento y la filosofía decimonónicos}

En el siglo XIX Hegel, para quien el devenir histórico no consiste en una acumulación irracional de acontecimientos, sino que se encuentra regido por una lógica determinada, instala en el pensamiento filosófico la importancia de la historia al postular la dependencia dialéctica del presente con los distintos momentos del pasado. El "saber absoluto", meta del despliegue dialéctico del espíritu, se alcanza sólo a través del ejercicio de la memoria, del recuerdo sistematizado, es decir, "científico", de las múltiples manifestaciones históricas del mismo. ${ }^{4}$ La razón se conoce -y se reconoce- conociendo las fases de su evolución histórica. La filosofía es filosofía de la historia e historia de la filosofía, al tiempo que la dimensión histórica deja entrever la necesaria historicidad de la filosofía. De esta manera, el modelo hegeliano otorga al devenir histórico un sentido expresado bajo la forma de una meta a la cual se arriba cuando se consuma el autoconocimiento del espíritu. ${ }^{5}$ Esta variante implica un acontecer regido por una lógica específica, la dialéctica, y una necesidad intrínseca al proceso de la historia, la autoconciencia del espíritu como manifestación del final del recorrido. Para Hegel: "La historia universal es la exposición del proceso divino y absoluto del espíritu, en

\footnotetext{
${ }^{3}$ De aquí toda la discusión con respecto a la escritura, en tanto práctica propiciatoria del olvido. Cfr., Platón. Fedro, 275a y $275 b$.

${ }^{4}$ Cfr., Löwith, Karl. De Hegel a Nietzsche, trad. Emilio Estiú, Bs. As., Sudamericana, 1974, pp. 53-54.

${ }^{5}$ Cfr., Ibíd., pp. 54, 55.
} 
sus formas supremas; la exposición de las series de fases a través de las cuales el espíritu alcanza su verdad, la conciencia de sí mismo". ${ }^{6}$

Paralelamente a su desarrollo, esta concepción resulta injustificable para los representantes de la escuela histórica, puesto que atribuyen a la filosofía el no respetar los hechos históricos e intentar organizarlos en función de un sentido construido a priori y proyectado, luego, sobre los mismos. ${ }^{7}$ De esta manera, historiadores como Ranke, Droysen y Dilthey intentarán separar el conocimiento histórico de aquellas perspectivas, vinculadas a la filosofía hegeliana, que piensan el devenir desde un punto de vista suprahistórico. Para lograrlo, sitúan el sentido de la historia en el mismo desplegarse de los acontecimientos, quitando toda finalidad que se encuentre localizada sea en el futuro o en el pasado. Los hechos históricos se interrelacionan, entonces, a partir de nexos causales y resultan ser más o menos significativos dependiendo de los efectos que puedan generar sobre otros sucesos. De esta manera, el "éxito", es decir, la "efectividad" de un acontecimiento, se convierte en criterio para determinar su valor histórico con referencia a otros eventos. ${ }^{8}$

La escuela histórica, tomando marcada distancia de la filosofía hegeliana, se repliega sobre el carácter "científico" del conocimiento, estrechando lazos con la metodología de las ciencias naturales. Desligados de un devenir fatalmente orientado hacia un fin preconcebido, los historiadores se concentran en el proceso histórico, en los nexos entre acontecimientos, y adoptan como modelo metodológico a la filología. ${ }^{9}$ Esta asociación del trabajo del historiador sobre el pasado a la actividad del filólogo sobre los textos permite evitar la clausura de la historia universal, tal como sucedía en la filosofía hegeliana una vez consumada la autoconciencia del espíritu. El historiador, puesto que como individuo forma parte del devenir histórico, conoce el pasado en un proceso que no finaliza nunca. La investigación científica es, de esta manera, y como pensaba Droysen, una tarea inacabable, dado que el historiador

\footnotetext{
${ }^{6}$ Hegel, G. W. F. Lecciones sobre la filosofía de la historia universal, trad. José Gaos, Madrid, Altaya, 1994 , vol. I, p. 76.

Al respecto señalaba Hegel: "A la filosofía, empero, le son atribuidos pensamientos propios, que la especulación produce por sí misma, sin consideración a lo que existe; y con esos pensamientos se dirige a la historia, tratándola como un material, y no dejándola tal como es, sino disponiéndola con arreglo al pensamiento y construyendo a priori una historia.", Ibid., p. 41. Y también Gadamer, Hans-Georg. Verdad y Método, trad. Ana Aparicio y Rafael Agapito, Salamanca, Sígueme S.A., 1971, vol. I, p. 256, "Debe recordarse cómo la escuela histórica se delimita a sí misma frente a Hegel. De algún modo su carta de nacimiento es su repulsa de la construcción apriorista de la historia del mundo."

${ }^{8}$ Cfr., Gadamer, Hans-Georg. Verdad y Método, ob. cit., pp. 259-260.

${ }^{9}$ Cfr., lbid., pp. 254-255.
} 
siempre se encuentra procurando reconstruir algo que, indefectiblemente, en el acto mismo de asirlo, se le escapa de las manos. ${ }^{10}$

Gianni Vattimo señala que pensar la "infinitud de sentido" del hecho histórico es posible puesto que la concepción de la historiografía descansa sobre el presupuesto de la verdad comprendida en tanto adecuación de la proposición al dato. ${ }^{11}$ Este modelo genera una situación paradójica, representada por un trabajo erudito proyectado hacia el infinito, en una relación asintótica con el -presupuesto- "verdadero sentido" de los hechos históricos. De aquí que la empresa del historiador adquiera cierto matiz teológico -especialmente en la obra de Ranke-, puesto que la investigación minuciosa del pasado, en tanto actividad inacabable, toma como referencia la existencia de un "entendimiento infinito" del sentido de los acontecimientos de la historia universal (Dios), al cual el historiador busca asemejarse a través de su tarea. Es en función de esto que Ranke puede señalar el parentesco que liga el historiador al sacerdote. ${ }^{12}$

\section{La época de la crítica a la concepción científica del conocimiento}

El auge del positivismo en la historiografía se convierte, durante el siglo XX, en uno de los blancos predilectos de ciertas vertientes del pensamiento filosófico. El socavamiento de la relación "recuerdo-conocimiento" se cimentó en torno de aquellas posiciones teóricas que se encolumnaron detrás de la empresa de destrucción del modelo positivista del conocer, teniendo como estandarte emblemático, por un lado, la fenomenología hermenéutica de Heidegger y, por otro, los juegos de lenguaje del Wittgenstein de las Investigaciones Filosóficas. Incluso Derrida, recuperando a Nietzsche y Saussure, sentó las bases para prescindir de cualquier referente extra-textual e hizo del hombre, en palabras de Dardo Scavino, un “....poeta antes que un científico; (puesto que) ama lo falso o las ficciones antes

\footnotetext{
${ }^{10}$ Crf., lbid., p. 274, “...a la investigación le conviene una infinitud distinta y cualitativa cuando lo investigado no ha de poder ser nunca contemplado por sí mismo... Para poder conocer, la investigación histórica sólo puede preguntar a otros, a la tradición, a una tradición siempre nueva, y preguntarle siempre de nuevo."

${ }^{11}$ Cfr., Vattimo, G. Diálogo con Nietzsche, trad. Carmen Revilla, Bs. As., Paidós, 2002, p. 90, "La mala infinitud del hecho, su nunca perfecta reproducibilidad, nos pone en guardia desde dentro, por decirlo así, contra la concepción de la verdad (por ahora historiográfica) como perfecta adecuación al dato." Vattimo hace hincapié en este punto para explicar la crítica nietzscheana a la concepción adecuacionista de la verdad, así como también para señalar el punto de partida del filósofo alemán en su intento de forjar un nuevo concepto de verdad.

${ }^{12}$ Cfr., Gadamer, Hans-Georg. Verdad y Método, ob. cit., p. 268. También Nietzsche en la segunda de las Consideraciones Intempestivas señala el carácter "teológico" de la historiografía al vincular el trabajo del historiador con el del sacerdote. Así como éste, aquel ha llegado a convertirse, para la cultura moderna y, especialmente, para el lego, en el portavoz del sentido del acontecer histórico. Como el clero en su momento, la casta de los historiadores se vuelve, de esta manera, digna de una cierta veneración social. Cfr., Nietzsche, F. Sobre utilidad y perjuicio de la historia para la vida, ob. cit., pp. 103-104.
} 
que la verdad". ${ }^{13}$ El impacto en la historiografía del desarrollo filosófico tributario de estas posiciones no se hizo esperar. En la década del '70 el norteamericano Hayden White arremetió contra la tradición de la ciencia histórica concentrándose en la dimensión del discurso historiográfico al destacar la familiaridad del mismo con la literatura. Emparentada con la ficción, la historia pasó a convertirse, desde la perspectiva de este autor, en un análisis de los estilos epocales a partir de los cuales la historiografía científica construye la narración del pasado. ${ }^{14}$

El debate en torno del carácter narrativo de la ciencia de la historia instaló una fuerte polarización entre, por un lado, la razón científica y, por otro, la imaginación literaria; entre hechos e interpretaciones. ${ }^{15}$ El problema planteado en estos términos no dejaba demasiadas soluciones al alcance de los historiadores. Quienes optaban por la razón y la defensa de los hechos históricos pecaban por no tener en cuenta una gran parte del desarrollo de la filosofía del siglo XX posterior al llamado "giro lingüístico". En contrapartida, aquellos que elegían las corrientes narrativistas y consideraban a la historia desde un punto de vista estético, en detrimento de la mirada tradicional, complicaban seriamente el estatuto de "ciencia" por el que la historia venía bregando desde el siglo XIX. La desaparición de la historia no era, en este contexto, una alternativa tan descabellada.

\section{El auge de la historia del pasado reciente}

La disolución del conocimiento, en el orden del pretendido acceso a la verdad y por ende a la realidad de los hechos históricos, liberó el componente del recuerdo que, a partir de las décadas de los '60 y '70, se manifestó a través del creciente interés por los estudios de memoria del pasado reciente. ${ }^{16}$ La disputa entre positivistas y narrativistas había creado las condiciones teóricas de posibilidad para el surgimiento de un campo problemático articulado

\footnotetext{
${ }^{13}$ Scavino, Dardo. La filosofía actual. Pensar sin certezas, Bs. As., Paidós, 2007, p. 36.

${ }^{14}$ Cfr., Laboranti, María y Godoy, Cristina. "La Historia en la Literatura y la Literatura en la Historia. Poética y Narrativa”, en Laboranti, María y Godoy, Cristina (Compiladoras). Historia y Ficción, Rosario, UNR Editora, 2005, pp. 14-15.

${ }^{15}$ Mudrovcic, María Inés. Historia, narración y memoria. Los debates actuales en filosofía de la historia, Madrid, Akal, 2005, p. 124, "Si bien el "giro lingüístico" en historia, en el contexto del debate narrativista que se dio a partir de la década del setenta, puso al descubierto las implicancias ideológicas (White, Barthes) de la narración en tanto estructura discursiva, no tuvo, empero, mayor impacto en la reformulación de lo que debiera entenderse por conocimiento histórico, sino sólo en lo referido a acentuar la dicotomía razón-imaginación, hecho-ficción."

${ }^{16}$ Existen otros motivos, de índole histórica, que también explican el surgimiento y constitución del campo problemático del "pasado reciente" y el auge, en consecuencia, de los estudios de memoria. Aquí he optado por privilegiar los aspectos teóricos del debate intelectual, puesto que me interesa destacar la importancia de la filosofía en relación con las ciencias sociales. Para una profundización de los elementos que, además de las teorías, jugaron un papel necesario en la constitución del campo (guerras mundiales, acontecimientos traumáticos, valor del testimonio, etc.) sugiero el texto de Franco, Marina y Levín, Florencia (Comps.). Historia reciente. Perspectivas y desafíos para un campo en construcción, Bs. As., Paidós, 2007.
} 
sobre los pocos bastiones epistemológicos que seguían en pie tras dos o tres décadas de agrios debates. En medio de este estado de cosas los estudios de memoria representaron, para los historiadores "más duros", la esperanza de que la historia mantenga en pie el monopolio legítimo del decir sobre el pasado; mientras que para los representantes del "textualismo" el nuevo campo problemático se constituyó en un laboratorio de experimentación teórica de posiciones que podían prescindir, sin mayor cargo de conciencia, de toda referencia a objetos extra-textuales.

Las dos grandes guerras del siglo XX pusieron en evidencia la complejidad del análisis del pasado reciente. Los positivistas encontraban el límite de la pretendida objetividad de la historia en la absoluta ausencia de neutralidad axiológica presente en los historiadores que se referían a la guerra, especialmente los alemanes. ${ }^{17}$ Los narrativistas se enfrentaron a la necesidad ética de tener que dar cuenta de las atrocidades del genocidio judío sin poder esgrimir el carácter ficcional de lo que se describía y denunciaba. En otras palabras, si bien la crisis del modelo de una ciencia histórica positivista había permitido redimensionar el espacio problemático del acceso al pasado dando lugar a la emergencia de la "historia reciente" como objeto de estudio y de disputa, al mismo tiempo trasladaba a ese nuevo campo problemático las discusiones jamás salvadas en el plano de la historia tradicional o universal. Un ejemplo claro lo constituye la figura del testigo y la importancia otorgada a los testimonios.

\section{EI testimonio y el sujeto de la experiencia}

El testimonio intenta recuperar una identidad histórica, individual y social que ha sido "desfigurada" durante determinados acontecimientos traumáticos. Testimoniar significa: a) un compromiso ético (puesto es un deber dar cuenta del horror acontecido), b) una acción política (introducir nuevos relatos con respecto al pasado reciente en lugares donde no existen o no circulan) y c) una terapéutica de la subjetividad.

Este auge del testimonio y su circulación en el espacio público es abordado críticamente por Beatriz Sarlo en un texto publicado en el año $2005 .{ }^{18}$ En el mismo, la autora reconoce como una "cultura de época" la superlativa significatividad otorgada a las narraciones realizadas en primera persona al momento de dar cuenta del pasado reciente, y se aboca a detallar los problemas que ello trae aparejado. Señala Sarlo: “el testimonio, por su

\footnotetext{
17 Cfr., Lvovich, Daniel. "Historia reciente de pasados traumáticos. De los fascismos y colaboracionismos europeos a la historia de la última dictadura argentina”, en Franco, Marina y Levín, Florencia (Comps.). Historia reciente. Perspectivas y desafíos para un campo en construcción, ob. cit., pp. 99-103.

${ }^{18}$ Sarlo, Beatriz, Tiempo pasado. Cultura de la memoria y giro subjetivo. Una discusión, Bs. As., Siglo XXI, 2005.
} 
autorrepresentación como verdad de un sujeto que relata su experiencia, pide no someterse a las reglas que se aplican a otros discursos de intención referencial, alegando la verdad de la experiencia, cuando no la del sufrimiento...." ${ }^{19}$ El principal problema que detecta Sarlo es la relación entre testimonio, experiencia y verdad. La particularidad del relato en primera persona es que reclama para sí el status de verdad en tanto un sujeto narra lo que le ha acontecido, su experiencia singular. En el encadenamiento de estos tres elementos se configura la imagen de un "sujeto fuerte" que hace transparentes los hechos que le acontecieron a través de un lenguaje no menos cristalino e impersonal. Esta vuelta a una matriz epistemológica moderna es denominada por Sarlo "giro subjetivo" y denunciada en su carácter paradojal, puesto que resulta contemporánea del intento de impugnación teórica de la misma más acabado: el "giro lingüístico". ${ }^{20}$

En relación con la historia reciente, el giro subjetivo tiene las siguientes consecuencias: a) reifica el pasado bajo la forma de la experiencia, b) estabiliza al sujeto que recuerda, dado que entre experiencia vivida en un determinado tiempo y momento del recuerdo no existe variación y c) ubica al dolor y al horror como garantes de la verdad del testimonio. ${ }^{21}$ De esta manera, la memoria autobiográfica, testimonial o en primera persona “...ha dado lugar a una sobrelegitimación de la posición de enunciación del testigo, quien emerge como el portador de "la" verdad sobre el pasado por el hecho de haber "visto" o "vivido" tal o cual acontecimiento o experiencia...". ${ }^{22}$ En otras palabras, el giro subjetivo se instala cómodamente en la matriz jurídica que asigna al testigo y a su testimonio un lugar clave con respecto a la "verdad de los hechos".

En contraposición con esta perspectiva se erige la posición de Agamben. En la obra Lo que queda de Auschwitz el filósofo italiano sostiene, en relación con la figura del musulmán, que éste representa al testigo-integral, ${ }^{23}$ es decir, a aquel que ha experimentado las condiciones más terribles del campo de concentración, que posee en el cuerpo la experiencia del horror, pero, justamente por ello, no la puede comunicar; ha perdido la palabra y hasta incluso su soporte, la racionalidad. El musulmán no es el testigo, el que habitó los campos de concentración y de exterminio y sobrevivió. El musulmán es la "vida desnuda", el resabio

\footnotetext{
19 lbid., p. 49.

${ }^{20}$ Cfr., Ibid., p. 22.

${ }^{21}$ Cfr., Ibid., p. 63, “...durante un tiempo... el discurso sobre los crímenes, porque denuncia el horror, tiene prerrogativas precisamente por el vínculo entre horror y humanidad que comporta."

${ }_{22}$ Franco, Marina y Levín, Florencia. "El pasado cercano en clave historiográfica”, en Franco, Marina y Levín, Florencia (Comps.). Historia reciente. Perspectivas y desafíos para un campo en construcción, ob. cit., p. 45.

${ }^{23}$ Cfr., Agamben, Giorgio. Lo que queda de Auschwitz. El archivo y el testigo. Homo sacer III, ob. cit., p. 165.
} 
biológico de lo que antes fuera un ser humano. El musulmán es el dueño de la experiencia medular del campo, pero no la puede decir. Lo único que nos ofrece es el silencio de lo incomunicable. Silencio que nosotros debemos interpretar, que nos provoca a la interpretación, sabiendo que sólo nos podremos acercar a la experiencia del exterminio, nunca poseerla. $^{24}$

El diagnóstico de Sarlo sobre el "giro subjetivo" y el auge del testimonio da cuenta de la persistencia de una concepción cara al positivismo: la transparencia del sujeto de conocimiento. En su lugar, la autora descarga los elementos del giro lingüístico para tornar clara la imposibilidad de la restitución de la experiencia o de su comunicabilidad. Finalmente, la propuesta pasará por un retorno a la literatura como expresión "más auténtica" de los horrores del pasado reciente, es decir, en torno del problema de contar la experiencia de un pasado traumático, Sarlo opta por recobrar las garantías del relato de ficción en detrimento de los hechos. La propuesta de Agamben es más compleja. La posibilidad de contar lo incontable, lo inexpresable, aquello de lo que no se tiene experiencia, es sólo eso, una posibilidad y, por lo tanto, un estado permanente de tensión expresado por la palabra prestada a quienes no la tienen. Esta perspectiva se sitúa, si no al margen de la relación polarizada de hechos y ficciones, en su mismo espacio intermedio, en el lugar mismo en donde se produce la oscilación entre la posibilidad de decir y el silencio.

\section{Las dos dimensiones hegemónicas del problema entre Memoria e Historia}

El estado de cosas actual dentro de la temática que venimos analizando podría dividirse en dos dimensiones problemáticas que se encuentran ampliamente transitadas en medida semejante. Todo el desarrollo precedente sobre la crítica a la tradición de la historiografía positivista desde los postulados del giro lingüístico y la importancia de la narrativa y la ficción, podría ser comprendido bajo el denominador común de “debates epistemológicos". Los mismos se mantienen oscilando sobre el binomio hechos-ficciones.

Por otro lado nos encontramos con lo que podríamos llamar la dimensión "ética" dentro de los problemas de la Memoria y la Historia. La misma se emplaza sobre el imperativo de memoria que establece el recuerdo, en particular de los acontecimientos horrorosos, como un deber. Este tipo de planteos se encuadra, en buena medida, detrás de los trabajos de Walter Benjamin. Partiendo del imperativo judío “Zakhor” (¡recuerda!), Benjamin entronca el

\footnotetext{
${ }^{24}$ Cfr., también Oberti, Alejandra y Pittaluga, Roberto. Memorias en montaje. Escrituras de la militancia y pensamientos sobre la historia, Bs. As., El Cielo por Asalto, 2006, pp. 235-254.
} 
marxismo con una concepción religiosa de la historia en la que el recuerdo de aquellos que se levantaron contra el poder -y se convirtieron en sus víctimas- es un acto de justicia, de reparación histórica. La mirada de Benjamin está puesta predominantemente en el pasado. Para redimir la historia de cada hombre que murió frente a una situación de opresión intentando cambiarla es necesario recordarla, pero con ello no basta, también es un deber retomar la lucha de aquellos que dieron sus vidas por el fin de la dominación y actualizarlas en el presente. El tiempo y la historia se vuelven para Benjamin aleatorios. La actualización de las luchas pasadas no asegura de por sí la victoria de la emancipación, pero tampoco garantiza la tranquilidad de los opresores de todos los tiempos. El futuro está abierto; cualquier cosa puede allí tener lugar. ${ }^{25}$

\section{La dimensión política: la ontología histórica de nosotros mismos}

En un pequeño texto llamado ¿Qué es la Ilustración?, ${ }^{26}$ Foucault se asumía como continuador del proyecto iluminista kantiano y se mostraba preocupado por las técnicas de creación de uno mismo en función de un aumento de la libertad individual. ${ }^{27}$ Conviene entonces establecer los parámetros teóricos entre los cuales se situaba la propuesta política del filósofo francés.

Para Foucault la modernidad no es una época o un conjunto de postulados filosóficos, sino una "actitud" (éthos). ${ }^{28}$ Lo "moderno" retomado no es ni más ni menos que el modo de vincularse a la realidad, a la época. Dicho modo está expresado en el texto kantiano Was ist Aufklärung? y consiste principalmente en una toma de distancia ante el presente que permitiría, en consecuencia, una reflexión crítica en torno de la diferencia entre el pasado histórico y el hoy. Para Foucault, el escrito de Kant sienta las bases para redirigir la filosofía hacia una indagación de lo que somos nosotros mismos en el presente en relación con el pasado. No lo que debemos ser, sino lo que hemos llegado a ser a lo largo de la historia. En otras palabras, la actitud ilustrada “...consiste en una crítica de lo que decimos, pensamos y hacemos, a través de una ontología histórica de nosotros mismos. ${ }^{29}$ La finalidad de este trabajo dista mucho de condecirse con la fenomenología hegeliana; pensar el presente en

\footnotetext{
${ }^{25}$ Cfr., Löwy, Michael. Walter Benjamin. Aviso de incendio. Bs. As., F.C.E., 2005.

${ }^{26}$ Foucault, Michel. “¿Qué es la llustración?”, en Foucault, Michel. Estética, ética y hermenéutica, Bs. As., Paidós, 1999, vol. III, pp. 335-352.

${ }^{27}$ Cfr., AA.VV. El infrecuentable Michel Foucault. Renovación del pensamiento crítico, Bs. As., Letra Viva y Edelp, 2004, introducción a cargo de Didier Eribon, pp. 20-25.

${ }^{28}$ Cfr., Foucault, Michel. “¿Qué es la llustración?”, ob. cit., p. 341.

29 lbíd., p. 347.
} 
relación con la historia es establecer los límites que nos configuran de una manera determinada, identificar las relaciones de poder que sostienen la producción de nuestra identidad, auscultar los focos de resistencia a los efectos de dominación, etc., pero en absoluto este trabajo pretende reforzar la identidad conferida. En otras palabras, establecer los límites de lo que somos es remarcar la diferencia con lo que podríamos ser más allá de dichos límites; se abre aquí un ámbito de experimentación y, en tanto tal, de autonomía. Sostiene Foucault: "Se trata, en suma, de transformar la crítica ejercida en la forma de la limitación necesaria en una crítica práctica de la forma del franqueamiento posible." ${ }^{30}$

La construcción de subjetividad como técnicas experimentales de sí se realiza en el marco de la dislocación entre lo establecido como universal y el reconocimiento de su contingencia. Es observable que en este punto el conocimiento histórico, bajo las figuras de la arqueología y la genealogía, desempeña un papel relevante. Es "histórico" sólo en la medida en que trata con materiales del pasado, pero no pretende para sí el estatuto de verdad de las ciencias historiográficas. ${ }^{31}$ En este sentido, el trabajo de revisar los límites de lo que somos a través del conocimiento histórico es una empresa filosófica, pero, al mismo tiempo, eminentemente política, puesto que aspira a instituirse a sí mismo como una "práctica de libertad". La filosofía es así una herramienta empleada a los efectos de realizar un "diagnóstico del presente", en consonancia con el escrito sobre la Aufklärung kantiano, con la finalidad de ser y pensar de otro modo. Actitud crítica y experimentación son dos elementos que confluyen en la noción de "subjetividad" foucaultiana. ${ }^{32}$

A contrapelo del encuadre moderno, la filosofía nietzscheana había brindado a Foucault los elementos suficientes para formular el trabajo histórico desde una posición claramente distante de las filosofías de la historia. En este sentido, la ontología histórica de nosotros mismos no involucra una toma de conciencia en el modo de la visión de la totalidad, sino más bien en la del recorte impuesto por el perspectivismo genealógico, lo cual implica el modelo del ojo del observador que puede verlo todo excepto el lugar de emplazamiento de su mirada. En este terreno, la propuesta foucaultiana de un trabajo histórico sobre nosotros mismos, encaminado a explicitar los límites que nos conforman, no significa de ninguna manera poder

\footnotetext{
${ }^{30}$ Ibíd., p. 347.

${ }^{31}$ Foucault, Michel. Historia de la sexualidad 2: el uso de los placeres, Bs. As., Siglo XXI, 2008, p. 15.

${ }^{32}$ Cfr., Ibíd., p. 15, "Es un derecho del discurso filosófico... explorar lo que, en su propio pensamiento, puede ser cambiado mediante el ejercicio que hace de un saber que le es extraño. El "ensayo" -que hay que entender como prueba modificatoria de sí mismo en el juego de la verdad y no como apropiación simplificadora del otro con fines de comunicación- es el cuerpo vivo de la filosofía, si por lo menos ésta es todavía hoy lo que fue, es decir una "ascesis", un ejercicio de sí, para el pensamiento."
} 
dar cuenta de la totalidad de los mecanismos normalizadores o de las técnicas de gobierno que articulan prácticas e identidades, sino más bien de una parcialidad, aquella que, en función del emplazamiento que tengamos en las relaciones de fuerzas -discursivas y no discursivas- se nos haga visible. ${ }^{33}$ Sobre este plano así conformado la práctica de la libertad es concebible por fuera del modelo de la soberanía del sujeto.

Dado que el trabajo sobre los límites no puede ser global, la libertad no debe ser comprendida como un ejercicio completo y soberano sobre todo lo establecido. Al contrario, en el ejercicio de resistencia por el cual pensamos las condiciones históricas que posibilitaron lo que somos descubrimos, al mismo tiempo, la posibilidad de dejar de estar sujetos a una identidad que se revela como contingente. En este sentido la libertad es una reacción que consiste en perdernos a nosotros mismos para ensayar otro tipo de subjetividad. Pero dado que lo social está conformado por múltiples relaciones de poder, el trabajo de la libertad sobre los límites se mueve alrededor de "parcelas" definidas, sea donde la dominación es mayor o, a lo sumo, donde se ha generado una práctica de resistencia capaz de desequilibrarla en sus focos de sostenimiento. La parcialidad de la práctica de la libertad conlleva que el proyecto de una transformación total de las estructuras sociales no sea algo contemplado por Foucault. No existe un lugar de llegada al que se accede por medio de una revolución, y donde -como sostenía Chomsky- la naturaleza humana pueda realizarse en todo su esplendor. Los proyectos globales no sólo presuponen la función de un sujeto soberano que los lleve a cabo desde un lugar privilegiado en relación con la conciencia de su tiempo, sino que implican una filosofía de la historia que marca las consecuencias necesarias del cumplimiento de determinados movimientos preestablecidos por dichas consecuencias.

La práctica de la libertad implica la seriedad y rigor de los trabajos genealógico y arqueológico en relación con los documentos y los archivos de la historia. Los límites que nos configuran no son lo suficientemente visibles ni de fácil acceso para volverlos explícitos a todos de una vez tras tomar conciencia de los mismos. Afirma Foucault al respecto: "Es cierto que es preciso renunciar a la esperanza de acceder alguna vez a un punto de vista que nos podría dar acceso al conocimiento completo y definitivo de lo que puede constituir nuestros

\footnotetext{
${ }^{33}$ Cfr., Veyne, Paul. "Un arqueólogo escéptico", en AA.VV. El infrecuentable Michel Foucault. Renovación del pensamiento crítico, ob. Cit., p. 60, nota № 107, "Quienquiera que esté inserto activa o pasivamente en una relación de poder grande o pequeña, es decir, todo el mundo, puede aceptar o rebelarse... pero esta rebelión no será una suerte de retorno de lo reprimido, retorno a una libertad original, a una verdadera naturaleza del hombre desalineado... nuestros franqueamientos de límites, son ellos mismos limitados, más aún, no podemos desplegar al respecto un conocimiento total en el sentido de saber completa y definitivamente dónde están nuestros límites."
} 
límites históricos. Y desde este punto de vista la experiencia teórica y práctica que hacemos de nuestros límites y de su posible franqueamiento es siempre limitada, determinada y, por tanto, una experiencia que hay que volver a empezar de nuevo. ${ }^{34}$ La práctica de la libertad, en este orden de cosas, es irremediablemente infinita ${ }^{35}$ e implica el reemplazo de la relación platónica invertida "recordar-conocer" por la de "recordar-experimentar". Esta última disposición de los elementos incorpora la subjetividad como instancia no definitiva e instala el vínculo con el pasado en una dimensión no asociada al problema del conocimiento planteado en los términos clásicos. De esta manera, tanto el debate ético como el problema de la certeza de los hechos históricos ${ }^{36}$ quedan desplazados ante un tratamiento político del pasado en la clave de la autoconstitución de sí mismo.

\footnotetext{
${ }^{34}$ Foucault, Michel. “¿Qué es la llustración?”, ob. cit., p. 348.

${ }^{35}$ Cfr., Ibíd., p. 348, "Pero, para que no se trate simplemente de la afirmación o del sueño vacío de la libertad, me parece que esta actitud histórico-crítica debe ser también una actitud experimental. Quiero decir que este trabajo efectuado en los límites de nosotros mismos debe, por un lado, abrir un dominio de investigaciones históricas y, por otro, someterse a la prueba de la realidad y de la actualidad, tanto para captar los puntos en los que el cambio es posible o deseable, como para determinar la forma precisa que se ha de dar a dicho cambio. Es decir, esta ontología histórica de nosotros mismos debe abandonar todos aquellos proyectos que pretendan ser globales y radicales."

${ }^{36}$ Recordemos que la denuncia que Nietzsche hacía recaer sobre la figura de Sócrates consistía justamente en señalar a éste como el primer pensador en haber anudado el problema de la verdad con el de la moralidad.
} 